\title{
Institutions as enablers of wellbeing: The Singapore Prison case study
}

\author{
John F. Helliwell
}

\begin{abstract}
Wellbeing research has long found a correlation between the subjective wellbeing of individuals and the quality of their private and public institutions. But which way do the causal arrows point, and what can be done to improve institutions? Only real-life experiments can answer these two questions convincingly.

Prisons are frequently considered schools for criminals rather than creators of wellbeing. Thus they provide a tough test for institutional changes intended to improve wellbeing. Since 1998 the Singapore Prison Service has converted its prisons into schools for life, thereby improving the lives of inmates, prison staff and the community at large. In so doing, the Prison Service exemplified five key lessons from subjective wellbeing research: the importance of social context, benevolence, trust, building positive outcomes, and top-to-bottom engagement in a shared purpose. By any measure, the results have been impressive, ranging from a one-third drop in recidivism to improved staff morale and better social connections between prisons and the rest of society.
\end{abstract}

Keywords: prisons, subjective wellbeing, subjective well-being, social capital, institutional reforms, quality of life, recidivism, community engagement, quality of government, felicitators

\section{Introduction}

Those who take subjective wellbeing seriously usually start asking, at some point, what can be done by individuals, families, neighbourhoods, organisations and nations to make lives better for themselves and others. This discussion usually centres at the level of the individual - what can individuals do, and how should they act, to produce better lives? The self-help literature tends to focus even more narrowly on what individuals can do to increase their own happiness. But the papers in this symposium instead describe felicitators - those whose ideas and actions increase the happiness of others. My own research has emphasized the social context of wellbeing, so I wished from the outset to find examples that demonstrate in real life some ways in which the social context can be altered to increase happiness. This paper illustrates how private and public institutions can change their structures or operations in ways that improve the social contexts in which people meet, move, work, play and live.

This paper illustrates five fundamental but often ignored results from wellbeing research, each of which refers to some aspect of the social context of wellbeing:

1) Process matters. How something is done matters even more to wellbeing than does what is actually done.

2) Benevolence is its own reward, but working together to do good things for others is a super-charged form of benevolence.

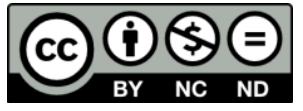


3) People routinely under-estimate the extent to which others can be trusted, leading to declines in social engagement and weakening of social norms.

4) Individuals and institutions could improve wellbeing by building positive outcomes rather than merely repairing damage and avoiding risks.

5) Shared engagement trumps top-down.

There are many inspiring examples of building or reforming institutions to create better lives. For example, Greg Mortenson's celebrated efforts ${ }^{1}$ to turn stones into schools (Mortenson 2009) illustrated the importance of bottom-up efforts, and the necessity and value of building trust one cup of tea at a time (Mortenson and Relin 2006). Especially in its emphasis on the time and listening it takes to build trust, and on the power of trust-driven local efforts to succeed in making fundamental changes, the story is inspirational and cautionary. BRAC ${ }^{2}$, a Bangladeshbased development agency, has shown how to raise material and subjective wellbeing together through mutual and effective engagement for a good purpose.

The Singapore Prison Service (SPS) reforms (Leong 2010) provide perhaps the most useful example, since they are not so widely known as the other examples. Facing all of the problems faced by prison systems throughout the world, Singapore's prison authorities took an amazingly broad approach focussed quite explicitly on the wellbeing of prisoners, staff, and community. They emphasized the building of connections and trust so as to combine prisoners, staff and the public in collaborative commitments to improve the lives of all. In the words of a case study presented to an intergovernmental meeting on new approaches to governance (Leong 2010, 11), "The case illustrates a government agency stepping beyond its traditional role of a guardian to that of a facilitator and enabler of change, first by clarifying the shared vision and purpose, and then creating channels, empowering and equipping its staff, other members of society, and even its beneficiaries to contribute". How different this is from the common view of prisons as social cesspits functioning primarily to punish criminals by incarceration while more often functioning as crime schools.

Reformed prisons that successfully exemplify key results from wellbeing research deserve to be described as Felicitators. If it is possible to show how the least tractable parts of public administration can be turned around dramatically, then the general case follows directly. If prison reforms can be shown to achieve not just conventionally measured success ratios but also to improve the lives of all whose interests usually clash in the management of criminal justice, then anything should be possible. Hence this paper spotlights the reforms of the Singapore Prison Service, making reference to other examples to help make the case that the Singapore successes can indeed be achieved in other institutions in other countries.

The paper proceeds by first describing five threads of wellbeing research that have special relevance to the paper. There follows a description of the main features of the Singapore reforms, showing how the reforms illustrate the main lines of wellbeing research to be outlined. There is also a short section surveying the limited amount of previous research linking

\footnotetext{
${ }^{1}$ http://www.ikat.org/ The Central Asia Institute is the NGO established to provide an administrative framework for what was in the first instance 'One man's mission to promote peace one school at a time' - from the cover of Three Cups of Tea (Mortenson and Relin 2006). What is most striking about the book is the nature of the lessons learned, and later applied, by Greg Mortenson, a grateful mountain climber who had promised to return to help the villagers of Korphe.

2 http://www.brac.net/ BRAC, formerly the Bangladesh Rural Advancement Committee, has for almost four decades developed and applied a range of strategies to engage and enable the Bangladeshi poor and illiterate. It now operates in many countries.
} 
subjective wellbeing research to the criminal justice system. The conclusion will attempt to assess the extent to which the Singapore experience offers ready lessons for others to follow.

\section{Five strands of wellbeing research}

When unravelling the social context of wellbeing, there are many ways of proceeding. This section lists a sample of relevant results under five different headings. Even together, these five points do not capture all the ways in which the social context matters for wellbeing. They were chosen instead with the aim of showing which elements of the social context were addressed by the reforms. The subsequent description of the reforms then shows how these principles were put into actions.

\subsection{Process matters}

Institutions often, and increasingly, focus on the attainment of specific outcomes, and are judged on what services they provide for those they serve. By contrast, research in subjective wellbeing suggests that much more depends on improving the social context than on the delivery of specific services. The best illustration of this, and one that dovetails nicely with the Singapore Prison reforms, is provided by the elder-care experiments of Knight, Haslam and Haslam (2010). When residents of an elder-care facility were being moved to a new building, the control group (the residents of the previously happier floor in the old facility) were given the best of professional designs for their new shared spaces, while the experimental group were invited to get together to make their own design decisions. ${ }^{3}$ By both their own assessments and those of the staff, the members of the experimental group were significantly more satisfied with their lives, were healthier, and more socially engaged after the move to the social spaces that they had designed together. These improvements were large and statistically significant, compared either to their own previous lives or the lives of the control group ${ }^{4}$. The experimental group also used and enjoyed their new collaboratively designed shared spaces more than the control group used their professionally designed shared areas.

This experiment did not come out of the blue; rather, it was a full-scale example of an accumulating set of results showing that shared autonomy matters in elder-care facilities (e.g. Kasser and Ryan 1999), and that maintaining social ties and identities helps individuals and groups to adapt successfully to change (e.g. Haslam et al. 2005, 2008). But what is striking is that two groups, both receiving the same high level of empathetic care, should have such different wellbeing outcomes by means of a small, but nonetheless important, change in the way in which the care was delivered. No extra resources were required, just the forethought to recognize that the process can matter even more than the service itself ${ }^{5}$.

\footnotetext{
3 "In addition to the provision of standard care, residents in the experimental (empowered) condition were...given the opportunity to make decisions about how to decorate their home's shared social spaces (i.e. the dining room, lounge and corridors). This involved selecting pictures and plants from a range of options. For this purpose, the residents took part in two formal meetings with the care-home managers, representatives of an interior landscaping company, and the researchers. Following these meetings, the residents were asked to make group decisions about the decor of the communal spaces in the new care home. At this point, the residents arranged their own formal and informal meetings to decide on the best designs. There was no interference in this process from the managers, care staff or researchers in relation to either aesthetic choices or spatial arrangement." (Knight et al. 2010, 1399).

${ }^{4}$ For example, the average reported life satisfaction of the experimental group rose from 4.6 before the move to 6.2 after the move. Before the move they were significantly less satisfied with their lives than were the control group, while after the move they were significantly more satisfied than the control group (Knight et al. 2010, 1404).

${ }^{5}$ See also Frey, Benz and Stutzer (2004).
} 


\subsection{Benevolence matters, and even more when it is shared}

A number of studies have shown that people are happier when they do things for others, to an extent even greater than they predict. For example, Dunn, Aknin and Norton (2008) found that experimental subjects assigned to spend money on others experienced greater happiness than did those assigned to spend the same money on themselves. Subsequent research in a crosscultural setting has confirmed with both survey and experimental evidence that this subjective wellbeing (SWB) payoff to benevolence is found everywhere, and thus has claims to be a psychological universal (Aknin et al. 2010). Meier and Stutzer (2008) find that the SWB rewards of volunteering are pervasive, but are even greater for those with less materialistic motivations.

Other studies have shown that time spent with others is generally associated with higher subjective wellbeing. For example, Helliwell and Putnam (2004) show that frequent interactions with friends and neighbours are tightly associated with higher subjective wellbeing. At a more basic experimental level, synchronized physical actions done (on a rowing machine) with others are more productive of endorphins that promote feelings of wellbeing and protect against pain than are precisely the same activities done on one's own (Cohen et al. 2010).

The subjective wellbeing benefits of social engagement are by now well-documented. What is less well known is how much of the gains flow to those who are the givers. Schwartz and Sendor (1999) found that when peer-support relations were established between pairs of multiple sclerosis patients, there were SWB gains for the recipients of this peer support. Only later did researchers consider whether there may have been gains also for the providers of the counselling. The gains to the providers turned out to be several times larger, and more sustained, than for those who were given support. This leads us to suspect that the benefits of the Singapore reforms, which are based on peer counselling among prisoners, may have produced the largest benefits among those providing the support.

\subsection{Trust matters to subjective wellbeing, and trustworthiness tends to be under-estimated}

Initial results linking trust and subjective wellbeing (e.g. Helliwell 2003) made use of the widely available yes-or-no responses to a standard social trust question: 'In general, most people can be trusted, or, alternatively, you cannot be too careful when dealing with people'. Across countries, answers to this question were correlated with differences in happiness, life satisfaction, traffic fatalities, suicide, and the frequency of return of experimentally dropped wallets, among other things (Helliwell and Wang 2011). Subsequent surveys have probed many different modes of trust: for example, of management, neighbours, co-workers and police; and found strong independent effects from each (Helliwell and Putnam 2004, Helliwell and Barrington-Leigh 2010, 2011). If there is a first among these equals, it is perhaps trust in management. For example, working where trust in management is just 1 point higher on a 10 point scale has the same impact on life satisfaction as an income one-third higher (Helliwell and Huang 2010).

A related finding is that where it is possible to distinguish perceptions of how much one should trust from the reality, it is perceptions rather than reality that determine subjective wellbeing. To give one example, it is possible to obtain comparable survey measures across countries of the past and expected future frequency of burglaries and attempted burglaries. In all countries, people think that the chances of being burgled in the next year are far higher than the average incidence of the previous year. Since this degree of over-estimation differs among countries, it is possible to see whether international differences in life satisfaction are related to either or both of the actual and expected likelihoods of burglary. The results show that it is only the expected future incidence of burglaries that is correlated with international differences in 
subjective wellbeing. Thus the systematic over-prediction of the risks of future burglaries is likely to be responsible for life satisfaction being unnecessarily low. People like to live in a world where other people can be trusted, but they frequently believe that people are less trustworthy than they actually are.

One more example may help to make this point. Several major surveys have asked respondents to report on a four-point scale how likely it would be for their lost wallets (assumed to contain \$200) to be returned if they were found, firstly, by a police officer; secondly, by a neighbour; and thirdly, by a stranger. In the Canadian sample the expected likelihood of wallets being returned by police officers was even higher than for neighbours; in some countries this ranking was reversed. In all countries, the expected likelihood of wallet return was judged lowest for wallets presumed to be found by strangers. By good fortune, a newspaper in Toronto decided to repeat the wallet experiment (originally done in a number of countries by the Reader's Digest) by dropping 20 wallets in metropolitan Toronto. In all cases the wallets were found (or not) by strangers, since the presumed owner was fictitious. Since there was already a large amount of survey evidence about the presumed likelihood of a wallet being returned if found by a stranger in Toronto, it was possible to compare the actual frequency of wallet return with what people living in the same city expected. The good news is that the actual frequency of wallet return was very high, about $80 \%$. The bad news is that it was expected to be less than $25 \%$. Despite the relatively small number of wallets dropped, the difference between the actual and expected wallet returns was so great that there is no chance that the two distributions are the same (Helliwell and Wang 2011).

It is well-established that trust and social connections are linked in both directions: where there is a climate of trust, people are more willing to reach out and make connections with others (Putnam 2000). In the reverse direction, people are more likely to trust those with whom they have regular social interactions. Hence the unjustified presence of mistrust hurts wellbeing in two ways. It lowers willingness to engage with others, and such engagements are themselves productive of wellbeing. And the lower trust perceptions also lead directly to lower levels of subjective wellbeing.

\subsection{Existence of positives trumps absence of negatives in determining wellbeing.}

It is a feature of the social sciences and related professions to wait until things go wrong and then try to make repairs. Think of medicine and the criminal law, or psychology. Positive psychology was started by those who saw something wrong with this approach. An electronic review of psychological abstracts since 1887 found that references to negative emotions outnumbered mention of positive emotions by 14 to 1 , even greater than the 7 to 1 ratio by which treatment outscored prevention (Myers 2000, 56). Since that time, psychologists have been comparing the effects of positive and negative emotions more systematically, and found the positives to be more important. For example, experiments have shown a systematic positive dose/response relation between a subject's initial positive affect and the extent to which he or she was able to ward off an experimentally administered cold virus, or to have milder symptoms if infected. Having negative affect did make colds more likely, but the effect was smaller than for the absence of positive emotions, and not significant (Cohen and Pressman 2006). In a different vein, the use of positive expressions in written work has been shown to be a strong predictor of future longevity in groups as different as a long-studied order of nuns (Danner, Snowdon and Friesen 2001) and a selection of eminent psychologists (Pressman and Cohen 2007). 
The common policy concentration on the repair of negative outcomes (the medical model), the punishment of those held responsible for bad outcomes (the criminal justice model), and the creation of laws and regulations designed to avoid bad outcomes (e.g. closing public spaces to reduce the chances of lawsuits) can at best restore the system to stasis by repairing damage and reducing the risk of future crimes and injuries.

But at what cost? The very laws and regulations that are intended to deal with actual and potential crime and disease usually have the effect of raising the perceived threats of bad events, reducing trust, and eliminating places and spaces available for people to mingle and meet, to engage in helping each other, and in other ways to build better lives.

\subsection{Shared engagement trumps top-down}

Only after this paper was substantially complete did I realise the extent to which the success of the Singapore Prison Service reforms rested on a seldom-studied bedrock of subjective wellbeing. It is broadly known that wellbeing in any organisation depends on shared values, shared identities, and a sense of engagement in a common purpose. It is less often noticed that it will all go better if everyone is having fun. Even less is said about the extent to which it is much easier to establish these critical elements of success if the whole process is driven as much or more from the bottom than the top, even if it needs to be empowered from the top. When reading about the Singapore Prison case, consider if it would have been possible at all if the enabling vision, and all of its innovative elements, had not flowed from horizontal collaboration among all parties. Success also required that senior management was willing to accept the risks of a process of change that was facilitated, rather than directed, from the top.

\section{The Singapore Prison Service reforms}

In 1998, the Singapore Prison Service (SPS) was facing pressures common to such systems around the world, particularly overcrowded prisons and shortages of staff due to difficulties in recruitment and retention. Although rehabilitation was always a goal, it was handled piecemeal by specialists. Such efforts were limited to work, education and religious counselling, and were not systematically monitored for effectiveness. The roles of prison officers remained mainly custodial.

New leadership came in 1998, and research was directed to assessing what sorts of promising reforms were taking place in other countries. In 1999, more than 800 staff members from all ranks of the prison system were brought together, in a series of retreats, dialogues and forums, to develop a shared vision for the prison system. What became clear during the course of a year of continuing discussions was that "most Prison Officers wanted to do more to help inmates under their charge become contributing members of society" (Leong 2010, 2). That in turn gave rise to a new shared vision that gave shape and direction to many of the strategies to follow. The vision clearly went beyond safety and security and into the rehabilitation and reintegration of the prisoners into society:

We aspire to be captains in the lives of offenders committed to our custody. We will be instrumental in steering them towards being responsible citizens, with the help of their families and the community. We will thus build a secure and exemplary prison system. (Leong 2010, 2)

One of the first substantive reforms was the design and introduction of a Housing Unit Management System to engage inmates and officers together to work toward the common goal of rehabilitation. Management recognized that this abrupt challenge to the traditional 'lock and 
bolt' mindset might pose problems for prison officers being asked to combine the roles of disciplinarian and rehabilitation officer. To ease this adaptation, and to learn more about how the two roles could best be made to co-exist, there was a year-long pilot project to test the new system within units that volunteered to do so. This combination of sequential evolution and bottom-up engagement was as central to the SPS reforms as it has been shown to be for wellbeing more generally.

Next, new rehabilitation programs were established to involve inmates more directly in prison operations, including peer support. This helped the workload of prison officers, improved inmate-staff relationships, increased mutual trust, and became a central part of the rehabilitation process. There were also a number of procedural reforms, including more use of home detentions, tele-visits and virtual court sessions for remand inmates. These reforms conserved resources, rewarded the higher levels of mutual trust, and gave prison staff "the confidence to explore new solutions beyond the prison walls" (Leong 2010, 4).

The most innovative parts of the SPS reforms involved 'breaking down' the prison walls, and attempting to unlock the 'second prison' when ex-prisoners return to a society not ready to accept them. The SPS leaders and staff realized, as the reforms evolved, that integrated in-care and co-ordinated after-care were not separate stages, and that reintegration had to begin on the first day of the first incarceration. For this to happen, links between the SPS and the community needed to change in fundamental ways. The SPS opened the doors of its prisons to the public, gave press tours and emphasized the success stories of reformed ex-prisoners. Media coverage and SPS ads began to change public attitudes towards prisons, and towards prison work, leading to increased recruiting success for both employees and volunteers. Co-ordinated aftercare networks were established, and brought into play by case workers for individual inmates as their sentences were ending.

The major reintegration branding instrument has been the Yellow Ribbon Project (YRP), introduced in 2004 as a framework for many activities designed to build and demonstrate the community's willingness to accept and enable successful new lives for ex-inmates. The range and content of these activities are impressive. There are annual song-writing contests for inmates, ex-offenders and after-care agencies, with inmates and headline artists from Singapore and abroad performing together in concerts to raise money for the Yellow Ribbon Fund. There are now regular runs that pass through prison grounds (the runners in the first such event included the Deputy Prime Minister). The Singapore Lions Club approached the YRP in 2009 to co-host a lunch for the elderly, with the meal cooked by inmates and served by ex-offenders. In that same year, inmates volunteered to fill the fun packs for the National Day Parade, and an ex-offender, a prison officer, and a social services officer took part in an Ironman race to raise S\$10,000 for the YRP. Since 2005, YRP conferences have brought together ex-offenders and groups involved with rehabilitation and reintegration to share experiences and build collective wisdom with an eye to further improvements.

The outcomes of the SPS reforms have been impressive on all fronts. The two-year recidivism rate, a classic measure of the overall success of a prison system, dropped from $44 \%$ for the pre-reform cohort released in 1998 to an all-time low of $23.7 \%$ for the cohort released in 2004. It has risen gradually since then, to $27.3 \%$ for the 2008 release cohort $(\mathrm{Ng} 2009,20$, updated). On the staff side, the SPS was voted one of the ten best employers in Singapore in 2007, and prison officer satisfaction with management grew steadily from $70 \%$ in 2001 to $84 \%$ in 2005 (Singapore Prison System 2006, Figure 7.3.4). Respect among prison inmates for prison officers rose from 58\% in 2002 to 92\% in 2006 (Singapore Prison System 2006, Figure 7.1.1). In the community, a 2007 survey found that 94\% knew about the Yellow Ribbon Project, and 70\% 
were willing to accept ex-offenders as friends or colleagues. In addition, the number of community volunteers, including a growing representation of ex-inmates, continues to grow (Singapore Prison System 2006, Figure 7.2.3.)

Since the SPS reforms were designed to solve perceived problems, rather than to facilitate subsequent research, they have not given rise to pre- and post- statistics sufficient to assess the overall success of the reforms, or to distribute the credit among the interlocking parts of the reform package. Horizontally-managed reforms that happen simultaneously and incrementally on many fronts have been shown to deliver higher subjective wellbeing in experimental contexts. But they are especially hard to monitor when they are taking place within a real prison system. However, the results quoted above, taken together, make a convincing case for the initial and continuing success of the SPS reforms.

Each of the main elements of the reforms illustrated one or more of the research strands listed; and all parties are thus far very satisfied with what has been accomplished. Singapore still has relatively high incarceration rates. Singapore's 2007 incarceration rates, at 250 per 100,000, were four times those of Japan, twice those of Canada and Australia, but still only onethird those of the United States $(\mathrm{Ng} 2009,18)$. In international terms, the system appears very efficient in terms of its low recidivism rates, absence of prison violence and continued maintenance of very low costs (Singapore Prison System 2006, Figure 7.2.1).

\section{Prisons and wellbeing}

There have been studies that have used experimental prison environments to study social psychology, and other studies have tried to apply subjective wellbeing research results to aspects of the criminal justice system. In the former instance, the best-known example is the Stanford prison experiment (Haney, Banks and Zimbardo 1973), in which students were recruited into roles of prison guards and prisoners. Those assigned to be guards subsequently fell into authoritarian attitudes, while the prisoners ultimately ceased resisting the guards' brutality and were even prepared to victimize other prisoners. The brutality of the guards and the suffering of the prisoners were so great that the experiment was terminated less than halfway through its intended two-week duration.

The more recent BBC prison experiments (Reicher and Haslam 2006 ${ }^{6}$ ) took a rather different tack, emphasizing the importance of the social structure within and between the groups of prisoners and guards, studying tyranny and resistance in tandem. In the Stanford experiments, tyranny trumped resistance, and the prisoners suffered. In the BBC prison study, the prisoners worked together in resistance, and the guards became a fragmented and ineffective force. In both cases, one group had a collective oppositional identity that it used to oppress the other. This conforms, in both cases, to the general model of a prison as a conflictual society, with guards and prisoners in opposition.

The magic of the Singapore Prison reforms was to break down that historic model of oppositional identities. The agents of reform sought and found a broad set of objectives that could be shared by prisoners and officers, and enabled shared identities as builders of better lives for all parties. There are earlier hints of these possibilities in the BBC prison study, where at two different stages, both at the beginning and the end, the guards and the prisoners made common cause, at first establishing a communal form, and at the end, in a less promising way, in accepting a harsher form of collective. Earlier Australian experiments (Lovibond, Mithiran and Adams 1979) provided a more direct blueprint for the possibilities achieved by the

\footnotetext{
${ }^{6}$ See also the website for the BBC prison study: http://www.bbcprisonstudy.org/bbc-prison-study.php?p=19.
} 
Singapore Prison reforms. These experiments showed that regimes involving greater mutual engagement and individuality for prisoners and officers led to significantly better results for both prisoners and officers. The Singapore Prison reforms go much further than such lab experiments, not only by being undertaken within prison realities but also extending the participation beyond the prison walls and into the community at large.

Previous applications of subjective wellbeing research to criminal justice topics have included proposing the use of estimated trade-offs from wellbeing equations to obtain better matching between the seriousness of an offense and the severity of the punishment (Bagaric and McConvill 2005). Bronsteen et al (2008) argue instead that evidence of adaptation creates an obstacle for all utilitarian approaches to the choice of appropriate punishments. Neither study is in the spirit of the SPS reforms, which are intended to avoid recidivism not by raising the perceived penalties but by improving the possibilities for prisoners to build preferable noncriminal lives. One SPS report includes a picture of a prison's tower and surrounding barbed wire with the caption "Most of our guests who checked out have no desire to return" (SPS 2006, 32).

The Singapore Prison Service reforms embodied all five lessons from the wellbeing research described earlier. First, the SPS leadership recognized immediately the importance of process. This involved spending time to develop a shared vision, and experimenting with different ways of implementing the vision. Second, the value of benevolence was demonstrated by the resonance and popularity of the many activities that unite inmates, ex-offenders, prison staff and the community in efforts designed to help others. Third, the need for and value of trust were central to the design of sequential reforms based on collaborative design and shared consultations. Fourth, the importance of having fun, and not just avoiding harm, is evidenced by many of the YRP activities, ranging from song-writing and runs to hosting meals for the elderly. Finally, the value of bottom-up initiative and engagement is apparent at each stage of the reforms, from a 'we-centred' leadership to a framework that encourages new initiatives and shares their lessons.

The Singapore Prison Service reforms did not draw directly from research on subjective wellbeing, but they certainly provide fine examples of how institutions in general, and prisons in particular, can be changed to make lives better for inmates, ex-offenders, families, staff and the community at large.

\section{Conclusion}

The most appropriate summary of the key lessons from the Singapore Prison Service reforms is drawn from their own report (Leong 2010, 11):

The case illustrates ... the possibilities that open up when a government agency begins not only to frame desired outcomes at the societal level, but also to help other members of the society to do likewise, leveraging its unique position and expertise to harness the collective efforts of society towards a common purpose. Finally, the case illustrates the impact that could result when a government agency beyond acting alone starts involving other stakeholders and members of society; tapping on their aspirations to co-create the change agenda, collective wisdom and strengths to design interventions and implement them, so that the sum of the whole is more than its parts.

As SPS work attracted new believers, first internally and then externally, more resources were made available to deepen their mission. Positive results in turn attracted more believers and resources - a reinforcing loop. Quality of 
relationships both within the organisation and with external partners enabled collective thinking, improved planning and actions, which led to higher quality outcomes that in turn grew relationships and deepened trust-improving outcomes - another reinforcing loop. 'Think big, start small' was where it seemed to have begun - a shared desire to improve the lives of those whom they served. The circle of influence started from individuals, organization cascading to the rest of community.

Each element of this description rings true when seen through the lens of wellbeing research. Every aspect seems ripe for application and emulation by others. The Singapore Prison Service reforms are an inspiring example of how institutions can be changed to improve wellbeing.

\section{Author}

John F. Helliwell

Canadian Institute for Advanced Research and University of British Columbia john.helliwell@ubc.ca

\section{Publishing Timeline}

Received 31 January 2011

Accepted 9 April 2011

Published 20 July 2011

\section{References}

Aknin, L.B. , C.P. Barrington-Leigh, E.W. Dunn, J.F. Helliwell, R. Biswas-Diener, I. Kemeza, P. Nyende, C.E. Ashton-James \& M.I. Norton (2010) 'Prosocial spending and well-being: cross-cultural evidence for a psychological universal' NBER Working Paper 16415. Cambridge: National Bureau of Economic Research.

Bagaric, M. and J. McConvill (2005) 'Giving content to the principle of proportionality: Happiness and pain as the universal currency for matching offence seriousness and penalty severity' Journal of Criminal Law 69(1), 50-74. http://dx.doi.org/10.1350/jcla.69.1.50.58954

Bronsteen, J., C. Buccafusco \& J. Masur (2008) ‘Happiness and punishment' Working Paper, University of Chicago Law School.

Cohen, E.E.A., R. Ejsmond-Frey, N. Knight \& R.I.M. Dunbar (2010) 'Rowers' high: behavioural synchrony is correlated with elevated pain thresholds' Biology Letters 6, 106-8. http://dx.doi.org/10.1098/rsbl.2009.0670

Cohen, S. \& S.D. Pressman (2006) 'Positive Affect and Health.' Current Directions in Psychological Science 15(3), 122-5. http://dx.doi.org/10.1111/j.0963-7214.2006.00420.x

Danner, D.D., D.A. Snowden \& W.D. Friesen (2001) ‘Positive emotions in early life and longevity: Findings from the nun study' Journal of Personality and Social Psychology 80, 804-13. http://dx.doi.org/10.1037/0022-3514.80.5.804

Dunn, E.W., L.B. Aknin \& M.I. Norton (2008) 'Spending money on others promotes happiness' Science 319, 1687-8. http://dx.doi.org/10.1126/science.1150952

Frey, B.S., M. Benz \& A. Stutzer (2004) 'Introducing procedural utility: Not only what but how matters' Journal of Institutional and Theoretical Economics 160, 377-401. http://dx.doi.org/10.1628/0932456041960560

Haney, C., C. Banks \& P. Zimbardo (1973) 'Interpersonal dynamics in a simulated prison' International Journal of Criminology 1: 69-97.

Haslam, S.A., A. O’Brien, J. Jetten, K. Vormedal \& S. Penner (2005) 'Taking the strain: social identity, social support, and the experience of stress' British Journal of Social Psychology 44(3): 355-70. 
Haslam, C., A. Holme, S.A. Haslam, A. Iyer, J. Jetten \& W.H. Williams (2008) ‘Maintaining group memberships: Social identity continuation predicts well-being after a stroke' Neuropsychological Rehabilitation 18(5/6), 671-91. http://dx.doi.org/10.1080/09602010701643449

Helliwell, J.F. \& C.P. Barrington-Leigh (2010) 'Measuring and understanding subjective well-being' Canadian Journal of Economics 43(3): 729-53.

Helliwell, J.F. \& C.P. Barrington-Leigh (2011) ‘How much is social capital worth?' In J. Jetten, C. Haslam \& S.A. Haslam, eds. The Social Cure: Identity, Health and Well-Being. Hove: Psychology Press.

Helliwell, J.F., C.P. Barrington-Leigh, A. Harris, \& H. Huang (2010) 'International evidence on the social context of well-being' In E. Diener, J.F. Helliwell \& D. Kahneman, eds. International Differences in Well-Being. New York: Oxford University Press. http://dx.doi.org/10.1093/acprof:oso/9780199732739.003.0010

Helliwell, J.F. \& H. Huang (2008) ‘How's your government? International evidence linking good government and well-being' British Journal of Political Science 38, 595-619.

Helliwell, J.F. \& H. Huang (2010) 'How's the Job? Well-Being and Social Capital in the Workplace' Industrial and Labor Relations Review 63, 205-28.

Helliwell, J.F. \& R.D. Putnam (2004) ‘The Social Context of Well-Being' Phil Trans R. Soc Lon. $B$ 359: 143546. Reprinted in F.A. Huppert, B. Keverne \& N. Baylis, eds., The Science of Well-Being. London: Oxford University Press, 2005, 435-59. http://dx.doi.org/10.5502/ijw.v1i1.9

Helliwell, J.F. \& S.Wang (2011) 'Trust and wellbeing' International Journal of Wellbeing 1(1), $42-78$.

Huppert, F.A., N. Baylis \& B. Keverne (2005) The Science of Well-Being Oxford: Oxford University Press.

Kasser, V.G. \& R.M. Ryan (1999) 'The relation of psychological needs for autonomy and relatedness to vitality, well-being and mortality in a nursing home' Journal of Applied Social Psychology 29(5), 935-54.

Knight, C., S.A. Haslam and C. Haslam (2010) 'In home or at home? How collective decision-making in a new facility enhances social interaction and well-being amongst older adults' Ageing $\mathcal{E}$ Society, 30, 1393-1418. http://dx.doi.org/10.1017/S0144686X10000656

Leong, Lena (2010) Story of the Singapore Prison Service: From Custodians of Prisoners to Captains of Life. Singapore: Civil Service College.

Lovibond, S.H., X. Mithiran, \& W.G. Adams (1979). 'The effects of three experimental prison environments on the behavior of non-convict volunteer subjects'. Australian Psychologist, 14, 273-287.

Meier, S. \& A. Stutzer (2008) 'Is volunteering rewarding in itself?' Economica 75, 39-59.

Mortenson, G. (2009) Stones into Schools. New York: Viking.

Mortenson, G. \& D.O. Relin (2006) Three Cups of Tea. New York: Penguin.

Myers, D.G. (2000) 'The funds, friends, and faith of happy people' American Psychologist 55(1), 56-67. http://dx.doi.org/10.1037/0003-066X.55.1.56

$\mathrm{Ng}$, P.J.H. (2009) 'Offender rehabilitation, community engagement, and preventing re-offending in Singapore' Singapore Prison System Resource Material Series 80.

http://www.unafei.or.jp/english/pdf/RS No80/No80 06VE Ng.pdf

Pressman, S.D. \& S. Cohen (2007) 'Use of social words in autobiographies and longevity' Psychosomatic Medicine 69, 262-9. http://dx.doi.org/10.1097/PSY.0b013e31803cb919

Putnam, R.D. (2000) Bowling Alone: The Collapse and Revival of American Community, New York: Simon \& Schuster.

Reicher, S. \& S.A. Haslam (2006) 'Rethinking the psychology of tyranny: The BBC prison study' British Journal of Social Psychology 45, 1-40.

Schwartz, C. E., \& M. Sendor (1999) 'Helping others helps oneself: response shift effects in peer support.' Social Science \& Medicine 48: 1563-75. http://dx.doi.org/10.1016/S0277-9536(99)00049-0

Singapore Prison System (2006) Captains of Lives: Renew, Rehab, Restart, Singapore, Singapore Prison System.

http://www.spring.gov.sg/QualityStandards/be/beaw/Documents/SQA Singapore Prison Service 2 006 Summary Report.pdf 